\title{
Mass Spectrometric Study of the Rate of Thermal Decompo- sition of Hydrazoic Acid
}

\author{
J. L. Franklin, ${ }^{2}$ Vernon H. Dibeler, and Preston P. Morris, Jx. ${ }^{3}$
}

\begin{abstract}
Hydrazoic acid vapor at low pressures $(0.15 \mathrm{~mm} \mathrm{Hg}$ or less), has been decomposed thermally and the rate of reaction studied mass spectrometrically at $265^{\circ}$ to $325^{\circ} \mathrm{C}$. Nitrogen and ammonia are the only reaction products, and no intermediates were observed. The disappearance of $\mathrm{HN}_{3}$ is first order and the reaction occurs on the walls of the glass reaction vessel. The experimental activation energy is 31 kilocalories per mole. The activation energy for the reaction $\mathrm{HN}_{3} \rightarrow \mathrm{NH}+\mathrm{N}_{2}$ must be at least 39 kilocalories per mole.
\end{abstract}

\section{Introduction}

Recent studies $[1,2]^{4}$ of hydrazoic acid have shown that the heat of the reaction

$$
\mathrm{HN}_{3} \rightarrow \mathrm{HN}+\mathrm{N}_{2}
$$

is 6 to $9 \mathrm{kcal} / \mathrm{mole}$. However Franklin et al. [2] have pointed out, from considerations of spin-orbital correlations that this reaction cannot proceed to the ${ }^{3} \Sigma^{-}$ground state of $\mathrm{NH}$ and instead would have to go to the lowest singlet $\left({ }^{1} \Delta\right)$ state of the radical. They estimated that this would be some $28 \mathrm{kcal} / \mathrm{mole}$ above the ground state, so that the activation energy for the decompositions would be about $37 \mathrm{kcal} / \mathrm{mole}$.

For so weak a bond, one would expect the molecule to decompose readily and a measure of the activation energy for the thermal decomposition of hydrazoic acid should ordinarily correspond to the activation energy of reaction. However, Ramsperger [3] and Meyer and Schumacher [4] have shown that the decomposition of hydrazoic acid in glass occurs on the surface of the vessels and presumably is catalyzed by the glass wall. Consequently, in such a system the activation energy would at best set a lower limit to the activation energy for reaction 1 . In spite of this limitation it was deemed worthwhile to study the kinetics of decomposition of $\mathrm{HN}_{3}$ and this paper presents the results of this investigation.

\section{Apparatus and Procedure}

A gas analysis mass spectrometer, Consolidated Electrodynamics Corporation type 21-102, was used to observe the rate of decomposition of hydrazoic acid and the appearance of decomposition products. The all-glass sample introduction system and 2-liter sample reservoir was similar to that described by O'Neal and Wier [5] and used by them for obtaining mass spectra of high molecular weight hydrocarbons. The sample reservoir volume was enclosed in a wellinsulated heating jacket and provided with thermocouples at several points. Isolation from the sample introduction manifold and the evacuating pumps was accomplished with a gallium-sealed, magnetically

\footnotetext{
1 This research was performed in part under the National Bureau of Standards Free Radicals Research Program, supported by the Department of the Army.

2 Guest scientist on leave from the Humble Oil Co., Baytown, Tex.

3 Present address, Convair, San Diego, Calif

4 Figures in brackets indicate the literature references at the end of this paper.
}

operated valve. The gallium valve, connecting tube, and the tube containing the effusive leak were wrapped with indiridually controlled heating tapes and with thermal lagging. Chromel-alumel thermocouples were provided at the valve, the leak, and at several intermediate points for temperature measurement. The maximum operating temperature was about $350^{\circ} \mathrm{C}$. At $300^{\circ} \mathrm{C}$, temperatures could be read and controlled with an uncertainty of about $\pm 4^{\circ} \mathrm{C}$.

Conventional mass spectrometric techniques were used for both chemical analysis and observation of the kinetics of decomposition. The sample reservoir also served as a reaction vessel. Prior to each run, it was thoroughly outgassed, usually overnight, at temperatures somewhat above the anticipated temperature range. At the start of a run and after a stable operating temperature was attained, neon was introduced into the reservoir to a nominal pressure of about $0.05 \mathrm{~mm}$ of mercury as measured by gas pipet. The mass range of 16 to 46 was scanned quickly to serve as a background. Then hydrazoic acid was added to a partial pressure of about $0.1 \mathrm{~mm}$ of mercury and the time of introduction was noted. In order to make initial observations as frequently as possible, only selected portions of the mass scale were scanned; e. g., $m / e=16$ to 20,28 to 32 , and 40 to 46. Each range uniformly required about $1 \mathrm{~min}$ to scan and the total lapsed time was noted at the start of each scan. Measurements were usually continued until the molecule ion of $\mathrm{HN}_{3}(m / e=43)$ had decreased to about 1 percent of the original abundance. The electron energy was $70 \mathrm{v}$.

Hydrazoic acid was prepared from sodium azide and 60 to 80 percent sulfuric acid. Preparations were carried out in a vacuum and the $\mathrm{HN}_{3}$ was purified by simple bulb-to-bulb distillation and by pumping on the product held at liquid nitrogen temperature. A mass spectrometric analysis of the product showed no impurities of higher molecular weight or of most simple gases condensible at liquid nitrogen temperature, the exception being occasional small amounts of ammonia. For reasons of safety the quantity of stored hydrazoic acid was limited to that giving a pressure less than $50 \mathrm{~mm}$ of mercury at room temperature in a 2-liter bulb. $\mathrm{As}_{\mathrm{N}} \mathrm{HN}_{3}$ was observed to decompose slowly in storage under these conditions, periodic analyses were necessary to assure material of suitable purity. 


\section{Results}

Table 1 summarizes the experimental data. Hydrazoic acid and neon concentrations after various reaction times are given in all runs. The nitrogen and ammonia concentrations are given for purposes of illustration only for run 6 . The only products of the decomposition of hydrazoic acid that were observed were ammonia and nitrogen. Although both hydrogen and hydrazine might have been expected none was ever found. Data from a typical experiment are plotted in figure 1. Here peak heights are corrected for differences in sensitivity and the mass 28 peak is corrected for the contribution from $\mathrm{HN}_{3}$. The curves for ammonia and nitrogen are characteristic of those for primary products of reaction formed simultaneously from the initial reactant.

It is shown later that the decomposition of hydrazoic acid is kinetically first order. For this to occur with ammonia as the final product, at least one transient intermediate is required. This might include $\mathrm{NH}$ or electronically excited $\mathrm{HN}_{3}$, as the first active species and various secondary intermediates such as $\mathrm{N}_{2} \mathrm{H}_{2}, \mathrm{NH}_{2}$, etc., can be postulated. Most mechanisms for the decomposition of $\mathrm{HN}_{3}$ have postulated $\mathrm{NH}$ as the initial product and we thought it worthwhile to try to establish this by identifying the products of its reaction with other materials. Specifically we made experiments in which large excesses of benzene and toluene were added to the reaction mixture and the products analyzed for postulated products of reaction. Thus, if NH were present, one might expect either biphenyl or aniline from the reaction in the presence of benzene, but none was identified, although the reaction in solution gives aniline. Similarly, in the presence of toluene one would expect bibenzyl, benzyl amine or dibenzyl amine to be produced but none was ever found. Rice and Freamo [6] report that cyanic acid was formed when $\mathrm{CO}$ was added to $\mathrm{HN}_{3}$ at high temperatures but the identity of masses of HNCO and $\mathrm{HN}_{3}$ rendered this method of identification unsuitable to our studies which depended upon mass spectra for identification and analysis of the reaction products. Similar considerations prevented our using ethylene which might have been expected to add NH giving ethylene imine.

Each mass spectrum was also examined carefully for evidence of transient intermediates but none was ever found. Of course NH would be obscured by the $\mathrm{NH}^{+}$peak from $\mathrm{HN}_{3}$. However, $\mathrm{N}_{2} \mathrm{H}_{2}$ and $\mathrm{N}_{2} \mathrm{H}_{4}$ if present would have been strong evidence for the presence of $\mathrm{NH}$ and $\mathrm{NH}_{2}$, respectively. In two or three runs small peaks at $m / e=30$ and 32 were found. However they always occurred together and no peak at $m / e=31$ was ever observed. Therefore it was concluded that the $m / e=32$ peak was due to $\mathrm{O}_{2}$ introduced as an impurity and the $m / e=30$ peak was $\mathrm{NO}$ formed by reaction $\mathrm{O}_{2}$ with either $\mathrm{N}_{2}$ or $\mathrm{HN}_{3}$. Thus it was impossible to obtam any direct evidence as to the nature of the active intermediates involved in the reaction.

Although the reaction appeared to be kinetically first order, it might conceivably have involved a

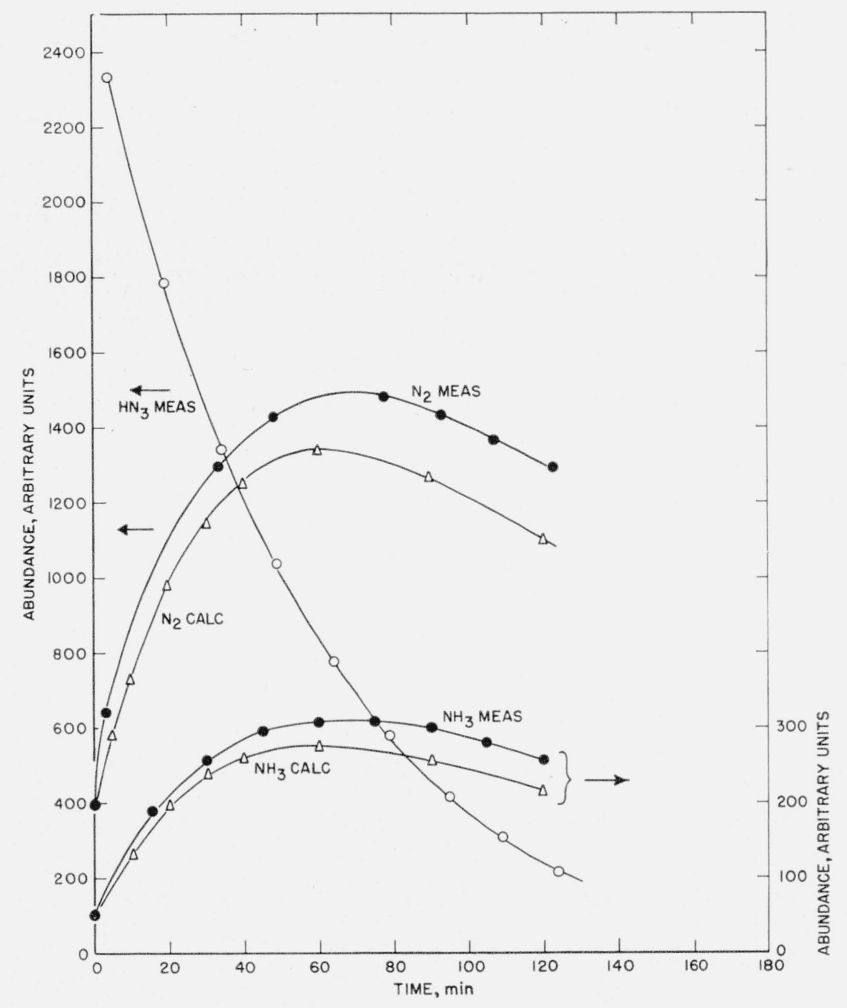

FIguRE 1. Variation of concentrations with time for run 6.

self-regenerating chain process. Accordingly a few percent of NO was added in one of the runs to ascertain whether the rate of reaction was markedly reduced thereby. It is evident from table 1 that NO caused only a small reduction in rate. This reduction may be enough to indicate that free radicals are involved in the reaction and are partly removed by the NO. This very small reduction in rate, however, clearly implies that a chain reaction is not being interrupted.

\section{Kinetics}

The gases in the reaction vessel passed into the mass spectrometer by molecular flow, the rate for various components of the gas mixture being inversely proportional to the square root of the mass. In all runs except one, neon was mixed with the hydrazoic acid in the reactor and the rate of disappearance of the neon, as indicated by the peak at $m / e=20$, was employed to calibrate the rate of flow of other components into the mass spectrometer. The rate of flow of neon from the reactor should be proportional to the neon concentration so that

$$
\ln \frac{\left[\mathrm{Ne}_{0}\right]}{[\mathrm{Ne}]}=k_{1} t
$$

where $k_{1}$ is the rate constant in reciprocal seconds. Data from a typical run plotted in figure 2 bear this out. 
TABLE 1. Summary of experimental data

(Peak heights (PH) are given in arbitrary units.)

\begin{tabular}{|c|c|c|c|c|c|c|c|c|c|c|c|c|c|c|c|}
\hline \multicolumn{4}{|c|}{ 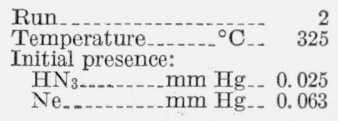 } & \multicolumn{4}{|c|}{300} & \multicolumn{4}{|c|}{$\begin{array}{r}4 \\
275\end{array}$} & \multicolumn{4}{|c|}{$\begin{array}{l}0.150 \\
0.140\end{array}$} \\
\hline \multicolumn{2}{|c|}{$\mathrm{HN}_{3}$} & \multicolumn{2}{|c|}{$\mathrm{Ne}$} & \multicolumn{2}{|c|}{$\mathrm{HN}_{3}$} & \multicolumn{2}{|c|}{$\mathrm{Ne}$} & \multicolumn{2}{|c|}{$\mathrm{HN}_{3}$} & \multicolumn{2}{|c|}{$\mathrm{Ne}$} & \multicolumn{2}{|c|}{$\mathrm{HN}_{3}$} & \multicolumn{2}{|c|}{$\mathrm{Ne}$} \\
\hline$t$ & $\mathrm{PH}$ & $t$ & $\mathrm{PH}$ & $t$ & PH & $t$ & PH & $t$ & $\mathrm{PH}$ & $t$ & $\mathrm{PH}$ & $t$ & $\mathrm{PH}$ & $t$ & $\mathrm{PH}$ \\
\hline \begin{tabular}{c}
$\min$ \\
0 \\
7 \\
23 \\
37 \\
52 \\
\hdashline- \\
\hdashline- \\
- \\
-
\end{tabular} & \begin{tabular}{c}
87 \\
6 \\
1 \\
0.3 \\
\hdashline- \\
\hdashline- \\
\hdashline-- \\
$-\cdots$
\end{tabular} & $\begin{array}{c}\min \\
-3 \\
18 \\
33 \\
48 \\
73 \\
--- \\
-- \\
--\end{array}$ & $\begin{array}{l}390 \\
285 \\
249 \\
240 \\
210 \\
\cdots- \\
-\cdots \\
--- \\
-\end{array}$ & $\begin{array}{c}\min \\
0 \\
4 \\
18.5 \\
34 \\
49 \\
64 \\
80 \\
94 \\
116 \\
146\end{array}$ & $\begin{array}{c}1740 \\
1140 \\
645 \\
365 \\
189 \\
90 \\
41 \\
21.5 \\
8.5 \\
3.5\end{array}$ & $\begin{array}{c}\min \\
-2 \\
17 \\
31.5 \\
47 \\
62 \\
78 \\
92 \\
113 \\
143\end{array}$ & $\begin{array}{r}2085 \\
1800 \\
1545 \\
1320 \\
1110 \\
940 \\
790 \\
620 \\
430\end{array}$ & $\begin{array}{r}\min \\
0 \\
3 \\
19 \\
34 \\
49 \\
64 \\
79 \\
94 \\
108 \\
124\end{array}$ & $\begin{array}{r}2700 \\
1954 \\
1593 \\
1290 \\
993 \\
729 \\
531 \\
386 \\
281 \\
138\end{array}$ & $\begin{array}{r}\min \\
-1 \\
17 \\
32 \\
47 \\
62 \\
77 \\
92 \\
106 \\
121\end{array}$ & $\begin{array}{l}750 \\
725 \\
637 \\
505 \\
476 \\
411 \\
353 \\
298 \\
253 \\
183\end{array}$ & $\begin{array}{r}\min \\
0 \\
4 \\
19 \\
34 \\
49 \\
64 \\
79 \\
94 \\
109 \\
141\end{array}$ & $\begin{array}{r}5800 \\
5440 \\
3934 \\
2980 \\
2301 \\
1773 \\
1353 \\
1017 \\
755 \\
409\end{array}$ & $\begin{array}{r}\min \\
0 \\
2 \\
17 \\
32 \\
47 \\
62 \\
77 \\
92 \\
107 \\
139\end{array}$ & $\begin{array}{r}1884 \\
1524 \\
1254 \\
1047 \\
882 \\
713 \\
589 \\
449 \\
336\end{array}$ \\
\hline \multicolumn{4}{|c|}{$\begin{array}{lr}k_{e}(\mathrm{Ne}) \mathrm{sec}^{-1} & 1.5 \times 10^{-4} \\
k_{r}+k_{e}\left(\mathrm{HN}_{3}\right) \mathrm{sec}^{-1}-- & 28.0 \times 10^{-4} \\
k_{r} \mathrm{sec}^{-1} & 27.0 \times 10^{-4}\end{array}$} & \multicolumn{4}{|c|}{$\begin{array}{l}\text { 1. } 82 \times 10^{-4} \\
\text { 7. } 7 \times 10^{-4} \\
6.44 \times 10^{-4}\end{array}$} & \multicolumn{4}{|c|}{$\begin{array}{l}\text { 1. } 67 \times 10^{-4} \\
3.41 \times 10^{-4} \\
2.27 \times 10^{-4}\end{array}$} & \multicolumn{4}{|c|}{$\begin{array}{l}2.17 \times 10^{-4} \\
3.11 \times 10^{-4} \\
1.65 \times 10^{-4}\end{array}$} \\
\hline \multicolumn{4}{|c|}{$\begin{array}{l}\text { Run } \\
\text { Temperature...- } \\
\text { Initial presence: } \\
\mathrm{HN}_{3} \\
\mathrm{Ne}\end{array}$} & 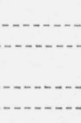 & 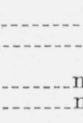 & $\mathrm{am} \mathrm{Hg}$ & $\begin{array}{r}6 \\
275 \\
0.075 \\
0.160\end{array}$ & \multicolumn{4}{|c|}{$\begin{array}{r}7 \\
300\end{array}$} & \multicolumn{4}{|c|}{$\begin{array}{r}\text { a } 9 \\
300\end{array}$} \\
\hline \multicolumn{2}{|c|}{$\mathrm{HN}_{3}$} & \multicolumn{2}{|c|}{$\mathrm{Ne}$} & \multicolumn{2}{|c|}{$\mathrm{N}_{2}$} & \multicolumn{2}{|c|}{$\mathrm{NH}_{3}$} & \multicolumn{2}{|c|}{$\mathrm{HN}_{3}$} & \multicolumn{2}{|c|}{$\mathrm{Ne}$} & \multicolumn{2}{|c|}{$\mathrm{HN}_{3}$} & \multicolumn{2}{|c|}{$\mathrm{Ne}$} \\
\hline $\mathrm{t}$ & $\mathrm{PH}$ & $t$ & $\mathrm{PH}$ & $t$ & PH & $t$ & $\mathrm{PH}$ & $t$ & $\mathrm{PH}$ & $t$ & $\mathrm{PH}$ & $t$ & $\mathrm{PH}$ & $t$ & $\mathrm{PH}$ \\
\hline $\begin{array}{r}\min \\
0 \\
4 \\
19 \\
34 \\
49 \\
64 \\
79 \\
94 \\
\mathbf{1 0 9} \\
\mathbf{1 2 4}\end{array}$ & $\begin{array}{r}2650 \\
2334 \\
1785 \\
1371 \\
1041 \\
777 \\
581 \\
419 \\
308 \\
221\end{array}$ & $\begin{array}{r}\min \\
0 \\
2 \\
17 \\
32 \\
47 \\
62 \\
77 \\
92 \\
107 \\
122\end{array}$ & $\begin{array}{r}2067 \\
1809 \\
1557 \\
1347 \\
1149 \\
952 \\
805 \\
699 \\
593\end{array}$ & $\begin{array}{r}\min \\
0 \\
3 \\
18 \\
33 \\
48 \\
63 \\
78 \\
93 \\
108 \\
123\end{array}$ & $\begin{array}{r}400 \\
640 \\
1040 \\
1300 \\
1430 \\
1500 \\
1480 \\
1430 \\
1370 \\
1295\end{array}$ & $\begin{array}{r}\min \\
0 \\
-15 \\
15 \\
30 \\
45 \\
60 \\
75 \\
90 \\
105 \\
120\end{array}$ & $\begin{array}{r}50 \\
190 \\
259 \\
295 \\
307 \\
310 \\
301 \\
286 \\
269\end{array}$ & $\begin{array}{r}\min \\
0 \\
4 \\
19 \\
34 \\
49 \\
64 \\
79 \\
94 \\
110\end{array}$ & $\begin{array}{r}2230 \\
1461 \\
768 \\
401 \\
190 \\
91 \\
41 \\
19 \\
9\end{array}$ & $\begin{array}{r}\min \\
0 \\
2 \\
17 \\
32 \\
47 \\
62 \\
77 \\
92 \\
108 \\
\end{array}$ & $\begin{array}{r}1900 \\
1674 \\
1440 \\
1215 \\
990 \\
800 \\
663 \\
530 \\
419 \\
---\end{array}$ & $\begin{array}{r}\min \\
0 \\
5 \\
20 \\
35 \\
50 \\
65 \\
80 \\
95 \\
110 \\
125\end{array}$ & $\begin{array}{r}2300 \\
1875 \\
1176 \\
702 \\
445 \\
277 \\
163 \\
93 \\
56 \\
31.5\end{array}$ & $\begin{array}{r}\min \\
0 \\
1 \\
16 \\
31 \\
46 \\
61 \\
76 \\
91 \\
106 \\
121\end{array}$ & $\begin{array}{l}-640 \\
623 \\
585 \\
563 \\
525 \\
498 \\
471 \\
451 \\
419\end{array}$ \\
\hline \multicolumn{8}{|c|}{$\begin{array}{l}k_{e}(\mathrm{Ne}) \\
k_{r}+k_{e}\left(\mathrm{HN}_{3}\right)_{-1} \\
k_{r}+\cdots\end{array}$} & \multicolumn{4}{|c|}{$\begin{array}{l}2.32 \times 10^{-4} \\
8.48 \times 10^{-4} \\
6.89 \times 10^{-4}\end{array}$} & & $\begin{array}{l}0.58 \times \\
5.73 \times \\
5.33 \times\end{array}$ & $\begin{array}{l}0^{-4} \\
0^{-4} \\
0^{-4}\end{array}$ & \\
\hline $\begin{array}{l}\text { Run... } \\
\text { Temper } \\
\text { Initial p } \\
\text { HN }_{3-} \\
\mathrm{NE}_{--}\end{array}$ & ature.- & - n & 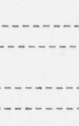 & mn & $\begin{array}{ll}\mathrm{C}_{--} \\
\mathrm{Hg}_{--} & 0 \\
\mathrm{Hg}_{--} & 0\end{array}$ & $\begin{array}{l}.010 \\
.010\end{array}$ & & & $\begin{array}{l}0.015 \\
0.015\end{array}$ & & & & - & $\begin{array}{l}0.020 \\
0.051\end{array}$ & \\
\hline & $\mathrm{HN}_{3}$ & & & & & & & $\mathrm{HN}_{3}$ & & & $\mathrm{Ne}$ & & & $\mathrm{HN}_{3}$ & \\
\hline$t$ & & $\mathrm{PH}$ & & $\mathrm{t}$ & $\mathrm{PH}$ & & $t$ & & & $\mathrm{t}$ & & H & $t$ & & $\mathrm{H}$ \\
\hline $\begin{array}{r}\min \\
0 \\
5 \\
16 \\
29 \\
39 \\
55 \\
69 \\
79 \\
89 \\
104 \\
114 \\
152\end{array}$ & & $\begin{array}{r}340 \\
340 \\
282 \\
240 \\
210 \\
177 \\
153 \\
140 \\
124 \\
108 \\
96 \\
63\end{array}$ & & $\begin{array}{r}\min \\
0 \\
-10 \\
25 \\
35 \\
50 \\
65 \\
75 \\
85 \\
100 \\
110 \\
148\end{array}$ & $\begin{array}{r}123 \\
- \\
97 \\
74 \\
69 \\
64 \\
60 \\
55 \\
51 \\
47 \\
40\end{array}$ & & $\begin{array}{r}\min \\
0 \\
4 \\
12 \\
17 \\
22 \\
31 \\
41 \\
51 \\
64 \\
76 \\
91 \\
106\end{array}$ & & & \begin{tabular}{r}
$\min$ \\
\hdashline 0 \\
8 \\
12 \\
18 \\
27 \\
37 \\
47 \\
57 \\
72 \\
87 \\
102
\end{tabular} & & $\begin{array}{r}129 \\
111 \\
103 \\
98 \\
89 \\
81 \\
76 \\
71 \\
63 \\
57 \\
53\end{array}$ & $\begin{array}{r}\min \\
0 \\
4 \\
15 \\
25 \\
35 \\
50 \\
65 \\
- \\
- \\
- \\
\end{array}$ & $\begin{array}{l}-.- \\
\\
-- \\
-- \\
-- \\
-- \\
--\end{array}$ & $\begin{array}{l}735 \\
633 \\
495 \\
343 \\
184 \\
101 \\
- \\
- \\
\end{array}$ \\
\hline $\begin{array}{l}k_{\theta}(\mathrm{Ne}) \\
k_{r}+k_{\theta}(\mathrm{H} \\
k_{r}\end{array}$ & {$\left[\mathrm{~N}_{3}\right)_{-}$} & 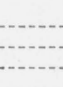 & & (n) & $\begin{aligned} & 1.05 \times \\
- & 1.84 \times \\
- & 1.12 \times\end{aligned}$ & $\left\{\begin{array}{c}10^{-4} \\
10^{-4} \\
10^{-4}\end{array}\right.$ & & & $\begin{array}{l}1.2 \times \\
3.06 \times \\
2.25 \times\end{array}$ & & & & -a & - & - \\
\hline
\end{tabular}

a Contains about 0.5 percent of NO. b Reactor packed with glass wool. 


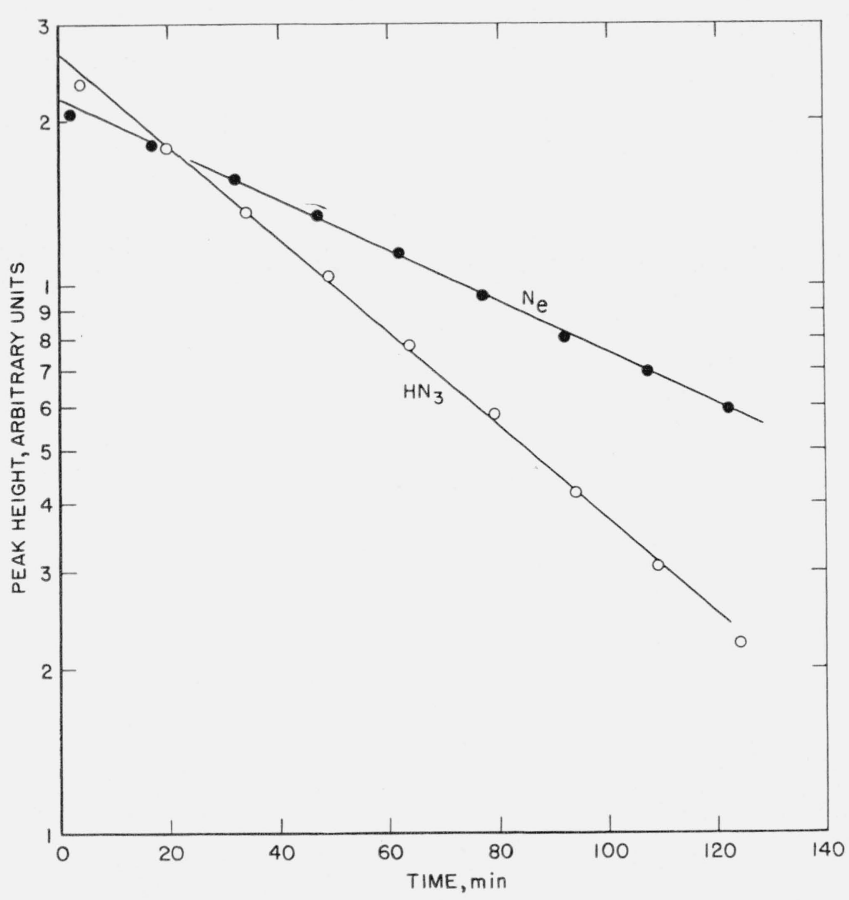

Figure 2. Semi-log plot of concentration versus time for run 6. Observed rate constants are $k_{\mathrm{N}_{e}}=1.8 \times 10^{-4} \mathrm{sec}^{-1}$, and $k_{H N_{3}}=3.29 \times 10^{-4} \mathrm{sec}^{-1}$.

Hydrazoic acid will disappear from the reaction vessel by reaction and by flow into the ionization chamber. The rate of disappearance is

$$
\frac{-d\left[\mathrm{HN}_{3}\right]}{d t}=k_{r}\left[\mathrm{HN}_{3}\right]^{n}+k_{2}\left[\mathrm{HN}_{3}\right]
$$

where $k_{r}$ and $k_{2}$ are respectively, the rate constant for reaction and for flow out of the reactor and $n$ is the order of the reaction. From figure 2 it appears that $\left[\mathrm{HN}_{3}\right]$ is an exponential function of time and that the reaction is first order i. e., $n=1$. However, since the over-all disappearance is influenced by the flow rate, which is first order, it seemed desirable to apply a more sensitive test of reaction order. For this the differential rate equation is more suitable than the integrated expression. Equation (2) can be rewritten

$$
\frac{-d \ln \left[\mathrm{HN}_{3}\right]}{d t}=k_{r}\left[\mathrm{HN}_{3}\right]^{n-1}+k_{2} \text {. }
$$

By calculating the slopes of tangents to the curve of $\left[\mathrm{HN}_{3}\right]$ versus time, such as that in figure 1 , $d \ln \left[\mathrm{HN}_{3}\right] / d t$ is readily calculated for various points along the curve. If this parameter varies with the concentration of $\mathrm{HN}_{3}$ the order can be obtained graphically since $k_{2}$ is known. If $d \ln \left[\mathrm{HN}_{3}\right] / d t$ is independent of the $\mathrm{HN}_{3}$ concentration the reaction is first order. A typical set of results is given in table 2 and shows that within experimental accuracy $d \mathrm{ln}$ $\left[\mathrm{HN}_{3}\right]$ is independent of the $\mathrm{HN}_{3}$ concentration and thus the reaction is indeed first order. Since $n=1$,
(2) becomes $-d\left[\mathrm{HN}_{3}\right] / d t=\left(k_{r}+k_{2}\right)\left[\mathrm{HN}_{3}\right]$ and $\left(k_{r}+k_{2}\right)$ can be determined from the slope of a plot of $\ln \left[\mathrm{HN}_{3}\right]$ against $t$. Also $k_{2}=k_{1} \sqrt{\mathrm{M}_{2} / \mathrm{M}_{1}}$, where $\mathrm{M}$ is molecular weight, so $k_{\tau}$ is determined. The rate constants for all runs were determined in this way and the results are given in table 1.

Ammonia and nitrogen are formed simultaneously by reaction and are withdrawn by effusion into the mass spectrometer. Since the total reaction is $3 \mathrm{HN}_{3} \rightarrow \mathrm{NH}_{3}+4 \mathrm{~N}_{2}$ we may write

$$
\begin{aligned}
\frac{d\left[\mathrm{NH}_{3}\right]}{d t} & =\frac{k_{r}}{3}\left[\mathrm{HN}_{3}\right]-k_{3}\left[\mathrm{NH}_{3}\right] \\
\frac{d\left[\mathrm{~N}_{2}\right]}{d t} & =\frac{4 k_{r}}{3}\left[\mathrm{HN}_{3}\right]-k_{4}\left[\mathrm{~N}_{2}\right]
\end{aligned}
$$

where $k_{3}$ and $k_{4}$ are, respectively, the rate constants for effusion of ammonia and nitrogen from the reactor. Integration leads to the following relations between concentrations and time:

$$
\begin{array}{r}
{\left[\mathrm{NH}_{3}\right]=\frac{k_{r}\left[\mathrm{HN}_{3}^{\circ}\right]}{3\left(k_{r}+k_{2}-k_{3}\right)}\left\{\exp \left(-k_{3} t\right)-\exp \left(-k_{r}-k_{2}\right) t\right\}} \\
+\left[\mathrm{NH}_{3}^{\circ}\right] \exp \left(-k_{3} t\right)
\end{array}
$$

$$
\begin{array}{r}
{\left[\mathrm{N}_{2}\right]=\frac{1.33 k_{r}\left[\mathrm{HN}_{3}^{\circ}\right]}{k_{r}+k_{2}-k_{4}}\left\{\exp \left(-k_{4} t\right)-\exp \left(-k_{r}-k_{2}\right) t\right\}} \\
+\left[\mathrm{N}_{2}^{\circ}\right] \exp \left(-k_{4} t\right)
\end{array}
$$

Figure 1 gives typical curves of $\left[\mathrm{NH}_{3}\right]$ and $\left[\mathrm{N}_{2}\right]$ against time obtained experimentally and by calculation from eq (6) and (7). The agreement leaves something to be desired but is close enough to be considered as confirmation of the method.

TABLE 2. Test of reaction order by differential rate equation for run 5

\begin{tabular}{|c|c|c|c|}
\hline$t$ & {$\left[\mathrm{HN}_{3}\right]$} & $-\frac{d\left[\mathrm{HN}_{3}\right]}{d t}$ & $-1000 d \frac{\left[\ln \mathrm{HN}_{3}\right]}{d t}$ \\
\cline { 2 - 3 } & & & \\
\cline { 1 - 2 } & 3,800 & 70.0 & 18.43 \\
20 & 3,200 & 60.0 & 18.73 \\
40 & 2,600 & 52.5 & 29.2 \\
50 & 2,150 & 40.0 & 18.6 \\
60 & 1,800 & 32.5 & 18.1 \\
70 & 1,500 & 26.3 & 17.6 \\
80 & 1.275 & 21.3 & 16.7 \\
90 & 1,075 & 18.7 & 17.4 \\
100 & 900 & 15.0 & 16.7 \\
110 & 750 & 13.8 & 18.4 \\
120 & 625 & 11.2 & 17.9 \\
130 & 525 & 10.0 & 19.1 \\
\hline
\end{tabular}

\section{Activation Energy}

An Arrhenius-type plot of reaction rate constant versus temperature is given in figure 3 . The data, although somewhat scattered, define a reasonably good straight line from which the activation energy $\mathrm{E}_{+}^{\dagger}$, is found to be $31 \mathrm{kcal} / \mathrm{mole}$. The rate constant is thus

$$
k=4.5 \times 10^{8} \exp (-31000 / R T) \mathrm{sec}^{-1} .
$$




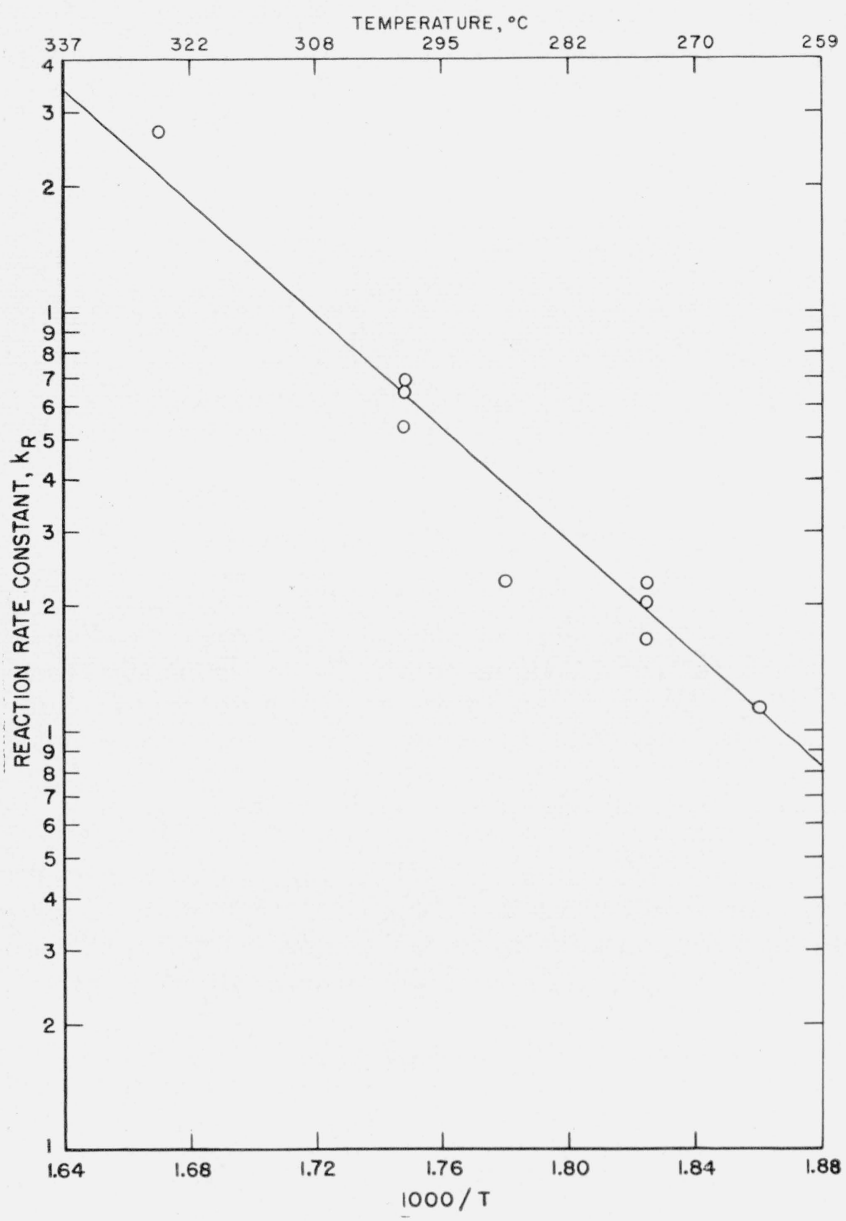

Figure 3. Arrhenius plot of activation energy.

Rice and Freamo [7] decomposed $\mathrm{HN}_{3}$ thermally at $1,000^{\circ} \mathrm{C}$ and allowed the gases to impinge on a cold surface, thereby obtaining a characteristic blue solid. By varying the distance from the furnace to the cold surface they obtained a half-life of about $10^{-3}$ seconds for the active species which formed the blue solid and which they concluded was NH. Their results might also be explained as giving the half-life of $\mathrm{HN}_{3}$ which decomposes to an active intermediate (such as $\mathrm{NH}$ ) of very short life. If we calculate the half-life of $\mathrm{HN}_{3}$ at $1,000^{\circ} \mathrm{C}$ from eq (8) we obtain a value of $3 \times 10^{-4}$ sec which, in view of the fact that the two sets of measurements were made under very widely differing conditions, is a reasonable check on the results of Rice and Freamo [7].

Glasstone, Laidler, and Eyring [8] show that the rate constant may be expressed in terms of the experimental activation energy

$$
k=\frac{k T}{h} \exp \left(2+\frac{S \ddagger}{R}-\frac{E \ddagger}{R T)} .\right.
$$

For reasons that will be given later (see eq 10, 11, and 12) the right-hand side of eq (9) must be multiplied by 3 to give the over-all rate constant. Taking
$\mathrm{E} \ddagger=31 \mathrm{kcal} / \mathrm{mole}$ and employing eq (8) and (9) we calculate $\Delta \mathrm{S} \ddagger$ to be $-26 \mathrm{e}$. $u$. This is much too large a negative entropy for a gas phase, first order reaction. The value is best explained as resulting from a reaction occurring on a solid surface. Indeed, such an entropy value corresponds approximately to the entropy of condensation of a gas.

In order to corroborate this conclusion a run was made using a reactor packed loosely with glass wool. The results are not as satisfactory as those obtained with an unpacked reactor, probably because diffusion was impeded by the packing. However, they do show that the added surface greatly increased the reaction rate. We may conclude, therefore, that the reaction occurs predominately on the glass surface of the reaction vessel.

Since the reaction is kinetically first order and the surface is involved, two kinds of mechanism can be adduced which would be in accord with our observations.

1. $\mathrm{HN}_{3}$ is adsorbed reversibly and the surface is sparsely covered. The adsorbed material undergoes a series of reactions resulting eventually in the production of nitrogen and ammonia which are desorbed. The following mechanism is one of several possibilities of this kind

$$
\left.\begin{array}{l}
\mathrm{HN}_{3}(\mathrm{~g}) \stackrel{\mathrm{a}}{\leftrightarrows} \mathrm{HN}_{3}(\mathrm{ads}) \\
\mathrm{HN}_{3}(\mathrm{ads}) \stackrel{\mathrm{b}}{\rightarrow} \mathrm{HN}(\mathrm{ads})+\mathrm{N}_{2}(\mathrm{~g}) \\
\mathrm{HN}(\mathrm{ads})+\mathrm{HN}_{3}(\mathrm{ads}) \stackrel{\mathrm{c}}{\rightarrow} \mathrm{N}_{2} \mathrm{H}_{2}(\mathrm{ads})+\mathrm{N}_{2}(\mathrm{~g}) \\
\mathrm{N}_{2} \mathrm{H}_{2}(\mathrm{ads})+\mathrm{HN}_{3}(\text { ads }) \stackrel{\mathrm{d}}{\rightarrow} \mathrm{NH}_{3}(\mathrm{~g})+2 \mathrm{~N}_{2}(\mathrm{~g})
\end{array}\right\}
$$

If one assumes that reaction $\mathrm{b}$ is the slow, ratecontrolling step and employs a steady-state treatment for all transient species the following rate expression is obtained:

$$
\frac{-d\left[\mathrm{HN}_{3}(\mathrm{~g})\right]}{d t}=3 k_{\mathrm{b}} K_{\mathrm{ads}}\left[\mathrm{HN}_{3}(\mathrm{~g})\right]
$$

where $K$ is the equilibrium constant for the adsorption of hydrazoic acid on glass.

2. $\mathrm{HN}_{3}$ reacts in the gas phase to give an active species which adsorbs rapidly and then undergoes a series of reactions with gaseous $\mathrm{HN}_{3}$. It is assumed that the surface is almost completely covered by the active species. As an example

$$
\mathrm{HN}_{3}(\mathrm{~g}) \rightarrow \mathrm{NH}(\mathrm{g})+\mathrm{N}_{2}(\mathrm{~g})
$$

$$
\left.\begin{array}{l}
\mathrm{HN}(\mathrm{g}) \leftrightarrows \mathrm{NH}(\mathrm{ads}) \\
\mathrm{HN}(\mathrm{ads})+\mathrm{HN}_{3}(\mathrm{~g}) \rightarrow \mathrm{N}_{2} \mathrm{H}_{2}(\mathrm{ads})+\mathrm{N}_{2}(\mathrm{~g}) \\
\mathrm{N}_{2} \mathrm{H}_{2}(\mathrm{ads})+\mathrm{HN}_{3}(\mathrm{~g}) \rightarrow \mathrm{NH}_{3}(\mathrm{~g})+\mathrm{N}_{2}(\mathrm{~g})
\end{array}\right\}
$$

Again, if one assumes the first reaction to be the slow, rate controlling step and applies a steady-state treatment, the reaction rate is found to be 


$$
\frac{-d\left[\mathrm{HN}_{3}(\mathrm{~g})\right]}{d t}=3 k_{1}\left[\mathrm{HN}_{3}(\mathrm{~g})\right]
$$

Both kinds of mechanisms give first order kinetics for the decomposition of $\mathrm{HN}_{3}$, but the over-all rate constant for mechanisms of type 1 includes the adsorption equilibrium constant whereas those of type 2 do not.

Mechanisms of type 2 usually prevail for the re-combination of atoms or simple radicals where a third body is required to remove the energy of reaction. It seems unlikely that this should be the case here since various reactions of the probable intermediates other than simple recombination can readily be visualized and these would provide a means of removing excess energy without the need of a third body or wall. Further, the rate of disappearance of $\mathrm{HN}_{3}$ by this mechanism is given simply by $3 k_{1}$ and so is independent of surface effects. This would not account for the negative entropy of activation and so mechanisms of this kind can be discarded.

Since the rate constant for mechanism 1 includes the equilibrium constant for adsorption of $\mathrm{HN}_{3}$ on glass, we may write

$$
\begin{aligned}
k_{\text {expt }} & =3 k_{b} \mathrm{~K}=\frac{3 k \mathrm{~T}}{h} \exp \left(\frac{\Delta \mathrm{S}^{\ddagger}}{\mathrm{R}}-\frac{\Delta \mathrm{H}^{\ddagger}}{\mathrm{RT}}-\frac{\Delta \mathrm{H}_{\mathrm{ads}}}{\mathrm{RT}}+\frac{\Delta \mathrm{S}_{\mathrm{ads}}}{\mathrm{R}}\right) \\
& =\frac{3 k \mathrm{~T}}{h} \exp \left(\frac{\Delta \mathrm{S}^{\ddagger}+\Delta \mathrm{S}_{\mathrm{ads}}}{\mathrm{R}}\right) \exp \left(\frac{-\Delta \mathrm{H}^{\ddagger}-\Delta \mathrm{H}_{\mathrm{ads}}}{\mathrm{RT}}\right) .
\end{aligned}
$$

$\Delta \mathrm{S} \ddagger$ for a unimolecular reaction is usually small and, as a first approximation may be taken as zero. The entropy of adsorption is negative and is often comparable in magnitude to that obtained for $\Delta \mathrm{S}^{\ddagger}$ in these studies.

In deriving eq (10) and (12) we assumed that the adsorption of $\mathrm{HN}_{3}$ was reversible and that equilibrium existed at all times between $\mathrm{HN}_{3}$ in the gas and on the surface. At equilibrium, $\Delta \mathrm{F}=\mathrm{O}$ and so

$$
\Delta \mathrm{H}_{\mathrm{ads}}=\mathrm{T} \Delta \mathrm{S}_{\mathrm{ads}}
$$

The heat of adsorption then, at temperatures near $300^{\circ} \mathrm{C}$ would be about $8 \mathrm{kcal} / \mathrm{mole}$. Since

$$
\begin{aligned}
& \mathrm{E}_{\text {expt }}^{\ddagger}=\Delta \mathrm{H}_{b}^{\ddagger}+\Delta \mathrm{H}_{\mathrm{ads}} \\
& \Delta \mathrm{H}_{b}^{\ddagger}=39 \mathrm{kcal} / \mathrm{mole} .
\end{aligned}
$$

The activation energy, $\Delta \mathrm{H}_{\mathrm{b}}^{\ddagger}$ is, of course, the activation energy of reaction $b$, the slow step in the process. In the example given this is shown as a bond breaking reaction but it might also be a simple elevation of the molecule to a higher electronic state. Since reaction b occurs on the surface, $\Delta H^{\ddagger}$ is not necessarily the same as it would be for the gas phase reaction. Further, it is probably somewhat smaller that it would be for the gas phase process, since otherwise, in view of the small entropy of activation of a first order reaction in the gas phase, the reaction would occur in the gas and not on the surface. Also, if the rate controlling step is some reaction other than the simple bond breaking process shown in the example then it follows that the activation energy for the gas phase reaction

$$
\mathrm{HN}_{3} \rightarrow \mathrm{NH}+\mathrm{N}_{2}
$$

is greater than $\Delta \mathrm{H}^{\star}$ since otherwise the latter reaction would occur at a greater rate and would be the process observed. It follows therefore that the measured $\Delta \mathrm{H}^{\ddagger}$ is equal to or less than the heat of activation of reaction $\mathrm{R} 1$; i. e., $\Delta \mathrm{H}^{\ddagger}$ for $\mathrm{R} 1$ is at least 39 $\mathrm{kcal} / \mathrm{mole}$. This is surprisingly close to the value of $37 \mathrm{kcal} / \mathrm{mole}$ estimated by Franklin et al. ${ }^{2}$ It would appear from these data that the true value of the activation energy of $\mathrm{R} 1$ is somewhat greater than this, but the amount would be difficult to estimate.

\section{References}

[1] P. Gray and T. C. Waddington, Proc. Roy. Soc. [A] 235, 481 (1956).

[2] J. L. Franklin, V. H. Dibeler, R. M. Reese, and M. Krauss, J. Am. Chem. Soc. 80, 298 (1958).

[3] H. C. Ramsperger, J. Am. Chem. Soc. 51, 2134 (1929).

[4] R. Meyer and H. J. Schumacher, Z. Physik. Chem. [A] 170, 33 (1934).

[5] M. J. O'Neal, Jr., and T. P. Wier, Jr., Anal. Chem. 23, 830 (1951).

[6] F. O. Rice and M. Freamo, J. Am. Chem. Soc. 75, 548 (1953).

[7] F. O. Rice and M. Freamo, J. Am. Chem. Soc. 73, 5529 (1951).

[8] S. Glasstone, K. J. Laidler, and H. Evring, The Theory of Rate Processes, p. 397 (McGraw-Hill Book Co., Inc., New York, N. Y., 1941).

Washington, January 22, 1958. 